\title{
Academic Insights into Promoting Indigenous Knowledge and Culture
}

\author{
Dr. Wahab Ali
}

\begin{abstract}
Indigenous knowledge is multi-dimensional encompassing the beliefs, practices, arts, spirituality, and other forms of traditional and cultural experiences that belong to indigenous communities globally. A university in Fiji has established a special Centre for iTaukei Studies (CIS) to preserve and recognize the knowledge of the indigenous people of Fiji commonly known as the iTaukei. The Centre apart from its cultural dimension principally in the form of songs, proverbs, stories, folklore, practices and rituals has adopted the western system of disseminating knowledge through publications, text books and teacher education programs. This paper presents a scholarly analysis of the historical origin of the Centre and the programs offered by it in promoting equal opportunity for the iTaukei students' access to formal as well as conservative education. While maintaining the importance of preserving the originality of the indigenous cultural identity and practices the paper will also highlight how the infusion of the cultures of the indigenous people and that of the Indo-Fijians, who have co-existed together for over 100 years have shaped the unique multicultural landscape in Fiji.

(Indigenous, iTaukei, cultural identity, multicultural and traditions)
\end{abstract}

\section{Introduction}

The definitions of Indigenous people are many and at times difficult to conceptualize due to their distinctive cultures relative to the dominant epistemic civilization. However, they all have certain commonalities such as groups' acceptance as the direct descendants of the original habitants of a region prior to colonization having distinctive cultural traditions and even tribal languages and dialects (Battiste \& Henderson, 2009; Gravelle, 2000; Mehta, Alter, Semali, \& Maretzki, 2013). Subsequently, they are referred to as the natives of a region prior to colonization having special registers of births to record those accordingly as indigenous people. In Fiji, the register is known as The Register of Births or Vola Ni KawaBula in accordance with the Government regulations (Ministry of iTaukei Affairs, 2011). As such, the indigenous people in Fiji are known as the iTaukei while the decedents of the Indians who were brought in Fiji from India by the British are commonly known as Fijians (Indo-Fijians or non iTaukei) as all citizens of Fiji are known as Fijians.

There is ample evidence that the indigenous people in the world have faced attack on their language and culture and use of their native knowledge without consent and acknowledgment (Battiste \& Henderson, 2009; Rasmus, 2002; Sockbeson, 2009). According to Batiste and Henderson (2009) about 500 people living in Canada, the United States, Australia, India, Peru, or Russia have faced a similar fate at the hands of colonizing powers. There is dearth of knowledge in this area in regards to the Fijian context and neither does this study make any inferences to this regard. Instead, this study tries to explore how a University has tried to cope with preserving and promoting the cultures and traditions of the iTaukei people of Fiji. The following section presents the context of the study; given that Fiji having faced a number of political upheavals is still regarded as an important player in the socio-economic environment of the South Pacific.

\section{Background and Context}

Fiji lies in the centre of the Pacific Ocean midway between the equator and the South Pole. Fiji is formally known as the Republic of Fiji. There are over 300 islands and has a total land area of 18333 square kilometers and spread over about 1.3 million square kilometers of the South Pacific Ocean. Most of the islands are small and scattered, thus geographically separated. Fiji became independent in 1970, after nearly a century as a British colony. Democratic rule was interrupted by two military coups in 1987, caused by concern over a government perceived as dominated by the Indo-Fijian community (descendants of contract laborers brought to the islands by the British in the 19th century). After the coup a 1990 constitution was promulgated that favored indigenous Fijians having political supremacy in Fiji and led to an exodus of Indians to other countries. The population loss resulted in economic difficulties, but enabled the indigenous Fijians to become the majority in Fiji. Amendments enacted in 1997 made the constitution more equitable and was recognized by the international community (Ministry of Information, 2006/7). However, the political upheavals did not cease and another coup took place in 2000 where again a democratically elected government was removed on gun point. Elections were held again but the life could not normalize when another coup took place in 2006. The Military under the advice of a military council ruled Fiji until the elections were held on $17^{\text {th }}$ September 2014. Fiji now has a new constitution that is crafted to put Fiji on track to becoming a modern and advanced nation in the South Pacific (Sayed-Khaiyum, 2014). 


\section{The Centre for iTaukei Studies}

The aim of the CIS is to provide a premier institution for the study of iTaukei society, economy, culture and tradition within the context of a multi-cultural Fiji. The Centre ensures that it is able to respond effectively to the needs of the indigenous Fijians. Through its programs, CIS actively encourages the development of an inclusive and united Fiji where all ethnic groups can interact more and develop a greater understanding of and respect for one another. The Centre's programs aim to actively encourage the development of an inclusive and united Fiji, where different ethnic groups can interact meaningfully and develop understanding and respect for one another. The CIS is viewed as an important driver of better integration of indigenous Fijians' concerns and contributions into an inclusive agenda of the development in Fiji with vibrant multi-ethnic cultures. Programs and research aims at examining topics and activities that will encourage cultural integration and interaction and a sense of inclusiveness among the different ethnic communities in Fiji.

\section{Aim of the Study}

The conundrums faced in promoting research and developments in indigenous studies are manifold. Given that, the assumption is that indigenous studies are vital to gain better perspective and understanding of the feelings and aspirations of the iTaukei people. As a result, the aim of this study is to explore the role of the CIS in promoting and preserving the indigenous cultural and traditions norms and practices. The study also investigates how and why the CIS has taken an indigenous academic perspective towards the dissemination of iTaukei language and culture. Finally the study tries to examine the fine threads of commonalities that exist between Indo-Fijians and them in co-existing together for over a century despite the previous political upheavals in the country.

\section{Significance of the Study}

The prime significance of this study is its contribution towards local literature in regards to activities promoting and enhancing iTaukei language and traditions. iTaukei people have an implicit belief that the accumulated and constantly refined wisdom of their ancestors and the elders in their communities has enabled their cultures to survive for millennia. This study will contribute towards filling in the gaps in local literature about traditional indigenous and indigenous academic perspectives of the CIS.

The findings will also be of value to the Ministry of iTaukei Affairs and the Ministry of Education in Fiji. They may realize the importance of the programs and services provided by the CIS and provide appropriate funding and grants for the establishment of a separate building reflecting indigenous architectural structure and design. The Ministry of Women Children and poverty Alleviation will also be informed about the initiatives of the CIS and appropriate assistance could be provided so that lifelong skills are taught that in turn would assist towards poverty alleviation through self employment. The study will also assist the curriculum planners at the Curriculum Advisory Section (CAS) of Fiji to better understand the role of CIS in preparation of curriculum materials that could be used in the school system. It will also provide valuable information to the Fiji Higher Education Commission (FHEC) in recognizing the important role it plays in providing quality education to the iTaukei students while maintaining their rich cultural identity at the University.

Findings will no doubt contribute towards reviewing of the role of the CIS so that its course offerings are more pertinent to the objectives of its establishment. Findings will present a scholarly analysis of the historical origins of the Centre and the programs offered by the centre in promoting equal opportunity for the iTaukei students' access to formal as well as conservative education. The iTaukei language has its own dynamics as there are different dialects and this study will establish how it is able to deliver its programs and at the same time maintain and celebrate the diversity of the different dialects. Literature on indigenous knowledge also concurs that the best approach to learning and indigenous knowledge is in the linguistic foundations of indigenous frameworks and paradigms (Battiste \& Henderson, 2009; Doxtater, 2004; Mehta et al., 2013).

This study will highlight the infusion of the cultures of the iTaukei people and that of the Indo-Fijians, who have co-existed together for over 100 years and how they have shaped the unique multicultural landscape in Fiji.

\section{Literature Review}

The article 14 of the United Nations Declaration on the Rights of Indigenous Peoples (United Nations, 2008) affirms that: Indigenous peoples have the right to establish and control their educational systems and institutions providing education in their own languages, in a manner appropriate to their cultural methods of teaching and learning (p. 7). Based on the above premise, this section presents some pertinent literature in regards to issues relating to indigenous people and their knowledge, cultures and traditional practices. While indigenous people have the right to their lands, territories and resources, often literature mentions their gradual elimination and eviction by governments (Greenwood \& Leeuw, 2007; McGregor, 2003). Greenwood and Leeuw (2007) in their discussion about issues facing the aboriginal people agree to the notion of "systematic marginalization faced by indigenous peoples, linking these to issues such as loss of land and culture"( $p$. 
49).Indigenous knowledge has passed down through many generations and are embedded in a context of language and orality and are evident in many of their stories and ceremonies. This is how they have been able to preserve their cultural norms and traditions.

Acting in accordance with protecting the rights of the indigenous people of Fiji, the Fijian Constitution guarantees the rights of ownership and protection of iTaukei, Rotuman and Banaban lands (The Government Of The Republic OF Fiji, 2013). The Ministry of iTaukei affairs has entrenched laws to preserve and safeguard the native land. This stance is strongly supported by Hill and Arlene (2002) who assert that "as indigenous people, our learning begins with the land, our mother and here we end with the land"(p. 282). Land is a pressing issue for many indigenous communities in the world. Literature discloses that in Malaysia the introduction of legislation concerning land has ignored the customary rights of the indigenous communities while the Kavet in Cambodia are affected by the devious political circumstances (Gamage, 2001). Evidently, Gamage (2001) proclaims a notable presence of negative experiences encountered by the indigenous communities enmeshed in the interplay of governments' interference with land acquirement and conservation issues. However, in Fiji the Ministry of iTaukei Affairs ensures that the Government develops, maintains and promotes policies that provide for the continued good governance and welfare of the iTaukei now and in the future (Ministry of iTaukei Affairs, 2011).

Subsequently, the Ministry of iTaukei affairs has embarked on a number of initiatives to preserve and promote language and culture. The iTaukei Institute of Language and Culture (IILC) based within the Ministry promotes the iTaukei language and culture and has produced and published the first ever iTaukei monolingual dictionary to be used in schools and by the general public(Ministry of iTaukei Affairs, 2011). Furthermore, the IILC plays a key role in adopting a National Research Framework to safeguard the iTaukei from being exploited of their tangible and intangible cultural heritage. According to Sillitoe (1998) these types of provisions enable researchers to better understand the ethical dilemmas when conducting research in indigenous studies. Indigenous knowledge is an emerging field of inquiry globally mainly for those interested in educational innovation and change. Indigenous science, arts, trading and exchange reflect the ecologically centred way of living and a sustainable humanity (Battiste \& Henderson, 2009). The culture and traditions of the indigenous people are essential to the renewal and revitalization of the indigenous knowledge.

It has been extensively documented that research in indigenous studies is growing especially in areas of indigenous languages, world views and experiences (Aseron, Wilde, Miller, \& Kelly, 2013; Bandias, Fuller, \& Larkin, 2014; Battiste \& Henderson, 2009). For generations the indigenous knowledge has been transmitted through ceremonies, songs, stories and dramatic representations. Each manifestation tells a history and intends to maintain the integrity of the people, the place and the cosmology. There is much to learn from the way indigenous knowledge has been transmitted from one generation to another without any formal schooling structures. Paradoxically, many countries depend on conventional education systems and the western style of formal education system (Bandias et al., 2014; Battiste \& Henderson, 2009). Fiji has also adopted a European model of schooling due to the early colonization by the British and the early missionaries. However, both the primary and secondary school curriculum in Fiji has components of iTaukei knowledge and culture embedded in many of the subject areas. None the less, the delivery of the lessons follow the conventional style as adopted in many western countries. The University through the Centre for iTaukei Studies advocates collaborative learning practices through storytelling and creative arts. It is able to use "talanoa" sessions quite effectively as it means solving issues through discussions and dialogues.

Talanoa is an indigenous word and is referred as a conversation, a talk or an exchange of ideas usually without formal settings in the Pacific (Halapua, 2002; Otunuku, 2011; Vaioleti, 2006). It allows people to engage in social conversation which may lead to critical discussions or knowledge construction that allows rich contextual and inter-related information. Talanoa sessions have been successfully used as data gathering tools in form of in-depth interviews as many Pacific customs and rituals are transmitted verbally (Ali, 2004; Sharma, 2000; Vaioleti, 2006). It seems then talanoa is one of the aspects that can be adopted as a contribution of the indigenous knowledge towards western knowledge and education. Talanoa removes the distance between researcher and participant, and provides research participants with a human face they can relate to. This is an ideal method of research because relationship is the foundation on which most Pacific activities are built (Merriam, 1998; Stake, 1995, 2000). It is anticipated that if talanoa is used effectively, it will produce rich mosaic information for local as well as international researcher. Farrelly and Nabobo-Baba (2014) further propose talanoa as an empathic apprenticeship that has the potential to enhance shared understandings between all human beings and could be used as a tool for decolonizing pedagogy and practice.

Indigenous academic perspective acknowledges the importance indigenous pedagogies in its diverse forms and manifestations. These different forms include oral traditions, community responsibilities and the creation of respect and reciprocity. Similar to that of the iTaukei centre at the University, the Faculty of Education at the University of Victoria (UOV) has programs that honours indigenous peoples, their cultures and ways of transmitting them from one generation to another (De France, 2013). Objective 19 of the Faculty of 
Education's Strategic Plan according to DeFrance (2013) is "to strengthen the faculty's capacity to create an environment welcoming of indigenous peoples and their ways of knowing and being" (p. 87). Based on this premise the Faculty offers various courses and programs in indigenous studies. Certificate in Aboriginal Language Revitalisation (CALR) is one of the programs offered by the Department. It is designed to strengthen the participants' understanding of the context and characteristics of language loss and recovery and to help students develop knowledge and strategies for language renaissance within the society (DeFrance, 2013).

Following a successful launching of a number of programs, the Faculty of Education at the University of Victoria approved a new Bachelor of Education program (BEd) on indigenous language revitalization. This program provides opportunities for students to strengthen and support the development of indigenous knowledge, languages and cultures. According to DeFrance (2013) the BEd is a laddered program delivered with a strong focus on building of fluency and analytical skills in linguistics and curriculum development. However, DeFrance (2013) agrees with Wilson (2008) that there are challenges in teaching indigenous students due to the "western paradigms of expectations and obligations within academic life"(p. 92). As such lecturers and teaching staff need to have an understanding of the cultural obligations and awareness and appreciation of their cultural responsibilities. Consequently, a better understanding of these responsibilities in turn can inform the educational pedagogies from an indigenous perspective. This being so, the teacher training course prepares student teachers with opportunities to learn from and within their local contexts (DeFrance, 2013).

There is ample evidence that indigenous perspectives enable students to uncover and reflect upon their cultural narratives through assignments and group activities (DeFrance, 2013; Greenwood \& Leeuw, 2007; Hill \& Arlene Holland, 2002; Mehta et al., 2013; Otunuku, 2011; Sillitoe, 1998). As such, literature entails that we all can learn from indigenous perspectives and become literate in understanding them and becoming literate in accepting the diverse worldviews and learns to work in contexts of diversity. This can lead to better understanding amongst the different ethnic groups in the community and the society at large.The insights drawn from such synoptic literature review are obvious and acceptable that people do not exist in isolation. Discourse on the challenges and perceived solutions in regards to indigenous education have been many and have brought together educators, historians, social scientists and academic researchers (Aseron et al., 2013). Notwithstanding these efforts, the United Nations (2008) advocated a position whereby indigenous peoples have been given the right to establish and control their educational processes, making use of their own language in a manner appropriate to their cultural methods of teaching and learning.

According to Aseron et al (2013) Indigenous Australians (also known as Australian Aboriginal and Torres Strait Islanders) have traditionally formed one of the most socially, economically and educationally disadvantaged community groups in Australia. This is despite numerous public and private interventions aimed at enhancing the participation of Australian Aboriginal and Torres Strait Islanders in education and generally, higher education. Aseron et al (2013) further asserts that despite more than 25 years of cultural awareness programs operating in Australia, Aboriginal and Torres Strait Islander people continue to find many institutions and other services as alienating and uncomfortable. The authors recommend that special incentives and policies needed to be enacted to advance indigenous quest for higher education. They firmly believe that indigenous students need the extra support and guidance with more qualified indigenous staff. Urgent action is needed in the building of and strengthening of indigenous studies and indigenous research. Taking the above sentiments in consideration Williamson and Dalal (2007) ascertain that educators and educational institutions need to build bridges between the Indigenous and Western knowledge systems to achieve meaningful outcomes, for Indigenous students in particular and for all students in general. In sum, this study will ascertain the role of CIS in this regard.

From such assertions it becomes easier to understand the important role languages can play in fostering better understanding and thus, remove undue misunderstandings and misinterpretations. This view is strongly endorsed by Hill and Arlene (2002) that language provides inroads into peoples' feelings and cultural ethos that are best conveyed in one's own language. Language provides "a foundation for indigenous education based on indigenous ways" (p. 282). They further promote using of 'cultural camps' where young people can learn from their elders in natural surroundings providing opportunities for interaction and hands on activities. Language is viewed as the most important tool for cultural obligations and ceremonial procedures. Considering the importance of language and cultural obligations the indigenous community in Australia achieved a milestone towards the beginning of this millennium when they opened doors to the first indigenous university in the Northern Territory. The Batchelor Institute of Indigenous Tertiary Education (BIITE) offers all nationalized as well as indigenous courses and programs to all students. Having discussed pertinent literature regarding indigenous studies, the following sections present the methodology implemented in this study.

\section{Research Methodology}

Consistent with contemporary social and educational research, this study was conducted in an interpretive paradigm. Approvingly, Miles and Huberman (1994) point out that the interpretivist approach is that 
which is concerned with providing a practical understanding of meanings and actions. As such this research was conducted from within an interpretive paradigm, and this had implications for the selection of an appropriate research design. Designs need to be consistent with the research paradigm chosen, thus a case study research design for the present study was felt to be the most appropriate for addressing the research questions. Subsequently, a mixed methods approach was adopted for this research to build on the strengths of both quantitative as well as qualitative methods (Creswell \& Clark, 2007). In the context of this research, methodological triangulation was achieved by combining input from qualitative data obtained from interviews with quantitative data from student enrolment and graduation statistics for the period 2010-2014 inclusive.

Semi-structured nterviews were used as the main data gathering tool for most of the study; the opinions and views of students and lecturers were needed to better understand the dynamics of the courses and programs offered by CIS. It is only through interviews that relevant data can be collected to address fully the research questions (Minichiello, Aroni, \& Hays, 2008). This understanding led to the selection of semi-structured interviews to be conducted in this study. Analysing textual information was the second method employed in this study. The documents viewed in this case were students' enrolment records and their graduation records. These documents provided valuable statistical information about the number of students doing the different programs offered by the CIS. According to Rose and Webb (1998) public records, personal documents and physical materials are three major types of documents available to researchers for analysis. Subsequently, the textual data and pictorials were obtained from the student affairs section and the archives at the University.

Selecting a research sample is a pressing issue frequently raised by researchers. Most qualitative studies have a smaller number of participants than quantitative studies because of the difficulty of managing and analysing interviews conducted on a large scale (Liamputtong \& Ezzy, 2008). Due to work and time constraints, it was impracticable to interview all the students as some of them were school teachers teaching in schools are scattered and situated in rural and remote areas. Literature supports that it is "very difficult for a single researcher to be involved in more than 100 long and complex social interactions" (Minichiello et al., 2008, p. 174). It was not possible to interview all the graduates of previous five years, as either they could not located or they were inaccessible due to their remoteness and maritime dwellings. Thus all 4 of the staff members and a manageable sample of 20 students (80\% of the total population) were purposefully selected because interviewing is time-extensive research (See Table 1).

Table 1: Student Population and Interview Research Sample

\begin{tabular}{|l|l|l|l|l|l|l|l|}
\hline Program & $\mathbf{2 0 1 0}$ & $\mathbf{2 0 1 1}$ & $\mathbf{2 0 1 2}$ & $\mathbf{2 0 1 3}$ & $\mathbf{2 0 1 4}$ & $\begin{array}{l}\text { Total } \\
\text { Population }\end{array}$ & $\begin{array}{l}\text { Research } \\
\text { Sample } \\
\mathbf{( 8 0})\end{array}$ \\
\hline $\begin{array}{l}\text { Bachelor of Arts in iTaukei Language and } \\
\text { Culture }\end{array}$ & 2 & 1 & 1 & 6 & 1 & $\mathbf{1 1}$ & $\mathbf{9}$ \\
\hline Diploma in iTaukei Language and Culture & - & 2 & 2 & - & 3 & $\mathbf{7}$ & $\mathbf{6}$ \\
\hline $\begin{array}{l}\text { Diploma in Teaching iTaukei Language } \\
\text { Literature and Communication }\end{array}$ & - & - & - & - & 6 & $\mathbf{6}$ & $\mathbf{5}$ \\
\hline Total & & & & & & $\mathbf{2 4}$ & $\mathbf{2 0}$ \\
\hline
\end{tabular}

Sample selection method is an aspect of the interpretive paradigm which "relies upon purposeful rather than representative sampling" (Lincoln \& Guba, 1985, p. 102). Moreover, purposive sampling is "very different from conventional sampling. It is based on information, not statistical considerations. Its purpose is to maximise information, not facilitate generalizations" (Lincoln \& Guba, 1985, p. 202). Teddlie and Tashakkori, (2009) agree with the views expressed by Lincoln and Guba (1985) and further state that purposive sampling is typically associated with "selecting a relatively small number of units because they can provide particularly valuable information related to the research questions" (p. 25). Nonetheless, $80 \%$ is a good representative of the total population. Subsequently a set of interview protocols were developed for the staff and the students. Figure 1 shows the questions that were asked during the interviews:

Interview Protocol

1. Has the establishment of the CIS assisted in the promotion and preservation of the indigenous culture and tradition? If so, how?

2. Has the establishment of the CIS assisted in the promotion of academic achievement for iTaukei students? If yes, explain how?

3. Has the CIS contributed towards achieving multicultural tolerance and understanding at the University? If yes, explain how?

4. What are some of the future plans or initiatives of the CIS?

5. How do you believe the services (programs) provided by the CIS can be improved?

Figure 1 Interview protocol 
In order for a research to be considered important, the findings need to be significant and be trustworthy. Likewise trustworthiness was enhanced by triangulation of data sources; that is the use of qualitative data to exemplify the quantitative information. Likewise, ethical issues were taken into consideration throughout the course of this study. To further maintain the ethical practices relevant information such as the aim and the purpose of the study were communicated well in advance to the participants of the present study while the pictorials were only used for analytical purposes.

\section{Findings and Discussion}

The nature of the research questions and the aim of the study underpin the data analysis procedures. The statistical information was systematically analyzed while the qualitative data was analyzed using thematic approach using coding after transcribing in its entirety resulting in emerging themes. The three C's of data analysis as recommended by Lichtman (2006) was used to move from the raw data to meaningful concepts. Coding, categorizing and concept identification made the reporting of the data more meaningful and comprehensive. Seemingly, as suggested by Yin (2003) all care was taken to ensure that appropriate interpretation of the information and techniques used in data analysis process were of the highest quality.

\section{Demographic Overview}

The trend in the iTaukei student population at the University shows a gradual increase over the years. A lot of iTaukei students are enrolled in other programs offered by the University. Although the numbers of students enrolled in the programs offered by the CIS are quite low as shown in Table 2, it does show a subtle increase from 2011.

Table 2: Number of iTaukei students enrolled in at the University

\begin{tabular}{|l|l|l|l|l|l|l|}
\hline Student Number & Year & & \\
\hline & 2010 & 2011 & 2012 & 2013 & 2014 & Total \\
\hline iTaukei students enrolled in other programs & 360 & 468 & 506 & 584 & 714 & 2632 \\
\hline iTaukei students enrolled at the CIS & 18 & 16 & 28 & 48 & 58 & 168 \\
\hline Total Number of iTaukei students & 378 & 484 & 534 & 632 & 772 & 2800 \\
\hline Non-iTaukei students & 672 & 778 & 889 & 1063 & 1292 & 4694 \\
\hline Total student population & $\mathbf{1 0 5 0}$ & $\mathbf{1 2 6 2}$ & $\mathbf{1 4 2 3}$ & $\mathbf{1 6 9 5}$ & $\mathbf{2 0 6 4}$ & $\mathbf{7 4 9 4}$ \\
\hline
\end{tabular}

The data provides valuable conventional information for the CIS as it needs to be more marketable and maybe offer more attractive programs and also be prepared to meet an influx of students in time to come. Programs and courses offered by the CIS would be discussed in detail in the forth coming sections. An important precursor to this current study is the recognition that not much of the existing research conducted to date perpetuates a recurring theme toward a deficit view of the ITaukei students in tertiary institutions in Fiji (Sillitoe, 1998). Although this study does not in any way supports or refutes a deficit view to this participation, a lingering sense of the drivers for research in this area is needed. The CIS offers three distinct programs of study. Apart from preparing teachers CIS graduates enjoy careers akin to iTaukei administrators, interpreters in courts, tour guides, translators of books and legal documents, reporters and journalists.

\section{Diploma in iTaukei Language and Culture}

This is a basic program in the study of iTaukei Language and Culture. The different courses in this program introduce students to listening and speaking iTaukei language. This is followed by reading and writing in iTaukei language. There is a specific course that introduces students to the use of languages in cultural context dealing with ceremonies, protocols and oral traditions. Students are immersed in creating literature in iTaukei language and finally they learn about their vanua, the land and the people in way of research projects. One of the interviewees stated during the interviews the "courses provided in the Diploma in iTaukei Language and Culture were very helpful and assisted me in my work as tourist guide" (P3, 2014). The letter ' $\mathrm{P}$ ' represents the participant while the number denotes the third participant followed by the year of research while ' $L$ ' represents a lecturer. Literature entails that we all can learn from indigenous perspectives and become literate in understanding them and becoming literate in accepting the diverse worldviews and learns to work in contexts of diversity (DeFrance, 2013; Greenwood \& Leeuw, 2007; Hill \& Arlene Holland, 2002; Mehta et al., 2013; Otunuku, 2011; Sillitoe, 1998). This can lead to better understanding amongst the different ethnic groups in the community and the society at large. Students responded as follows in regards to programs and how they could be improved:

In this program there is a whole course on promoting cultural practices, like cooking and preserving of food. This course teaches us the importance of preserving our culture so that the information can be passed on to the new generations. Having practical sessions will be better in future (P14, 2014). 
While another participant who works as a tour guide recounts his experiences as:The best aspect of this program is on ceremonies and iTaukei protocols. As a tour guide, it has enabled me to perform my duties well. The tourists are very happy with my explanations and often I am given a lot of tips but inclusion of some conversational Hindi would be better (P15, 2014)The Diploma in iTaukei Language and Culture equips students with knowledge and skills required for a better understanding of the iTaukei culture and tradition. This creates a better understanding and an appreciation of the various customs and traditions of the iTaukei people.

\section{Diploma in Teaching iTaukei Language, Literature and Culture}

This is a teaching program that prepares students to a life of teaching in secondary schools in Fiji. Students are introduced to a set of courses that prepares them to meet the challenges of teaching iTaukei language, literature and culture. Teaching and learning iTaukei language and translating theories and practice prepares students to understand the psychology of the teaching learning process. Methodologies of teaching and writing and promoting cultural teaching and learning are two courses that enable students to better understand teaching approaches. One of the interviewees, who is teaching in a village school considered it to be:

A good program with good content making future teachers know about the teaching methods. As a teacher now, I can reflect and say the teaching experience sessions I had was great. Maybe the practical sessions could be increased so that we could get more experience (P9, 2014). The courses discuss what is generally understood as the three main teaching styles in educational pedagogy: direct instruction, inquiry-based learning and cooperative learning. Through these three teaching methods, teachers can gain a better understanding of how to govern their classroom, implement instruction and connect with their students. Technical and procedural aspects of teaching are addressed, which includes planning for teaching and managing a classroom, as well as the delicate balance between the technical aspects of teaching and the intellectual and moral demands of teaching.

\section{Bachelor of Arts (with a major in iTaukei Language and Culture)}

The Bachelors degree is the highest level of academic qualification offered by the iTaukei Centre. This degree is specially designed for iTaukei students who want to become school teachers. It focuses on Indigenous education and teaches strategies to help graduates make the curriculum more responsive to Indigenous students. Given the complex nature of the needs of the indigenous students, the degree provides students a broader inquiry into Indigenous identities in the contemporary world by including units from anthropology, education, psychology and human geography enabling them to gain essential skills for working in a diverse and challenging world. The Indigenous Studies program provides a unique perspective that pertains to such disciplines as anthropology, linguistics, philosophy, psychology, religious studies, and sociology. It is overwhelming to note that the CIS is intending to offer a double major program in future. The Director of the CIS stated that the double major will explore a range of contemporary issues affecting iTaukei peoples' life experiences and aspirations. In so doing, the double major will also encourage students to examine the issues of personal and national identity, and the relationship between these, themselves and other races of people living in Fiji. Apart from academic courses, the CIS offers activities that aim to encourage students to understand the past and contemporary experiences of Indigenous people of Fiji.

\section{Research in iTaukei Language and Culture}

The CIS is involved in researching into the iTaukei way of life. Analytical analysis shows that research has been done in a nearby village. Findings further reveal that the research undertook the collecting and documenting oral iTaukei histories, including relationship ties, social structures and those between people and the physical and spiritual environment. Environmental and cultural changes have an impact on traditional food systems and nutrition of Indigenous Peoples worldwide. The CIS promotes an understanding of iTaukei peoples, their traditions, aspirations and participation in local, national and international communities. There is ample literature to support the views that indigenous knowledge in its diverse forms and manifestations can inform academic perspectives and practices through different forms (Battiste \& Henderson, 2009; De France, 2013; Mehta et al., 2013). These different forms include oral traditions, community responsibilities and the creation of respect and reciprocity. The CIS intends to become a leader in providing quality education in indigenous knowledge and practice within traditional and contemporary contexts. Research usually focuses on the interplay of traditional values, identity, spirituality and the creative imagination in art, literature and oral story.

\section{Written iTaukei Resources}

Recognizing the need to have written materials in iTaukei for use in tertiary studies, CIS has embarked on translating relevant books in iTaukei language. Subsequently, they have also identified topics on which short stories can be written that can be used as texts by iTaukei students in primary and secondary schools. Research shows that learners whose first language is not English, make faster progress in reading, and read with deeper 
comprehension, when the material is familiar to them, even though the language may not be (Aseron et al., 2013; Bandias et al., 2014; Battiste \& Henderson, 2009; Doxtater, 2004). The CIS intends to venture into writing but is affected by lack of financial as well as qualified iTaukei staff members. One of the lecturers lamented the lack of resources and staff to fully implement the writing process. It is not that qualified personnel are not available, but the University's financial position inhibits recruiting more staff members to undertake writing iTaukei texts and prepare other teaching and learning resources. Adding up to the setbacks, one of the lecturers raised her concerns as follows: There are fourteen confederacies in Fiji with different dialects, cultural practices and art and craft. Courses need to be redefined so that more areas in indigenous culture and tradition can be studied. It is a rich and complex culture that needs more written records with comprehensive research (L2, 2014)

Written texts play a very important role in the lives of the iTaukei people. Many of their legends and stories need to be captured and recorded before they are lost in the midst of western stories and music videos. For iTaukei that sense of place is not limited to architecture and many preservation issues focus on retention of native languages, subsistence hunting and fishing, and other cultural and social practices. One of the staff members expressed sadness while recollecting her schools days where she learnt about Alexander Bell and Neil Armstrong but were not informed about Ratu Sir Lala Sukuna. "We were even punished for speaking in iTaukei language as we were all supposed to speak in English" (L3, 2014). She believes students in Fiji should be taught about traditional methods of food cooking and preservation using iTaukei language and this view is strongly endorsed by Hill and Arlene (2002) who argue that language provides inroads into peoples' feelings and cultural ethos that are best conveyed in one's own language. Understanding cultural attitudes, tribal protocol, and sensitivity to native issues takes years and they need to be captured in textbooks and educational videos that could be used as educational resources in Fijian schools. This would in turn educate non iTaukei about the indigenous culture and in turn promote better understanding and cooperation amongst all races of people who call Fiji their home.

\section{Promotion and Preservation of iTaukei Culture and Tradition}

One of the most exciting aspects of historic preservation today is the way in which native peoples are seeking to protect their culture and tradition. Since language provides vital insights into a people's worldview and is an integral component of any culture, the CIS offers courses and programs that enable students to appreciate their cultural beliefs and traditions. Findings reveal that despite CIS is a small unit at the University, it is slowly making its impact in regards to the promotion and preservation of the iTaukei culture and tradition. The number of students enrolled in all the 3 academic programs show a gradual increase while Diploma in teaching iTaukei Language, Literature and Culture seems to be well taken by the students. According to one of the staff members:The mission of CIS is to promote intrinsic values through lectures, research and workshops on indigenous culture and tradition. Engaging and involving students to take part in cross cultural programs and activities promotes better understanding amongst all students (L2, 2014)

Yaqona is served during an official ceremony to a chief guest as a token of appreciation and there is a special ritual and protocol that needs to be followed. Yaqona is also consumed as a social drink during social gatherings and weddings. The drinking of yaqona has integrated into the many functions of the non iTaukei people in Fiji and abroad wherever people of Fiji have settled in. This has enabled a better understanding and tolerance amongst all people and now it is common in non-iTaukei weddings to watch non-iTaukei performers doing meke and fire dances. As such the iTaukei people can be adequately satisfied that due to this co existence of the two major races of people in Fiji for over a century has helped creating a better understanding and even sharing of each other's cultural practices and to some extend the belief systems.

There is substantial research evidence that support the view that culture and traditions of the indigenous people are essential to the renewal and revitalization of the indigenous knowledge that can be transmitted through ceremonies, songs, stories and dramatic representations (Aseron et al., 2013; Bandias et al., 2014; Battiste \& Henderson, 2009; Greenwood \& Leeuw, 2007; Maslen, 1999; Ward, 2011). Despite having a number of coups in Fiji, the people are very resilient and have always bounced back as the grass root people always display the same love and affection for one another and programs like that offered by CIS can be a catalyst to better understanding, tolerance and reconciliation. Quantified data derived from interviews show that most of the students $(90 \%)$ strongly agree that CIS has been able to actively promote and preserve the iTaukei culture and traditions and create a better relationship with all others.

\section{Promotion of Academic Performance}

Improving academic performance is an important means by which individuals can realise their full potential and make positive, informed choices about their lives. Educational experiences can affect job prospects, help the acquisition of socially valued qualities of character and behaviour, and support participation in social, cultural and economic life. Achieving these benefits for the indigenous students requires 
empowerment and support structures, like that of a CIS. Education is a key factor that is known to build resilience and has potential to improve outcomes for iTaukei students. Improving rates of participation and attainment of iTaukei students in tertiary education system are key to improved living standards. Research shows that unless indigenous students learn about the forces that shaped their history, their values, customs and language, they will never be able to know their self potential and CAS tries to honour these through its programs (De France, 2013). One of the lecturers made the following comment in this regard:

All our graduates are employed in primary and secondary schools in Fiji. Many of the graduates have indicated their wish to further their studies to postgraduate level while the Diploma graduates are eager to complete their degree programs. Diploma graduates from other tertiary institutions are pursuing the UniFiji iTaukei program for better recognition in the employment sector (L1, 2014).

On a similar note, one of the graduates made the following observations that are in alignment with the comments that follow:

All my colleagues who graduated have been absorbed in the civil service. They have better grades in iTaukei courses as compared with the grades they achieved in other subject majors. (P5, 2014)

As stated above, analytical findings reveal that iTaukei students enrolled at CIS are more academic oriented and complete their studies with good grades. Analytical data further reveals that there are fewer iTaukei at risk students at CIS as compared to those enrolled in other programs of studies.

It can be unequivocally stated that CIS has played a positive role in establishing a high standard for the students who are enrolled in its programs. In turn these students are also able to produce better results in their other courses they do towards completing their respective programs of studies. However, further in-depth research is warranted in this field. The CIS provides an opportunity for the iTaukei students where they can openly share their views and discuss issues concerning their assignments and projects. This finding gets support in the views expressed by Aseron et al (2013) that indigenous students need the extra support and guidance from indigenous staff. Collaborative working and learning is ingrained in the iTaukei way of living and for them the community process of working together is often more important than the structure that is created. Working in groups and having talanoa sessions undoubtedly has intrinsic connotations with the iTaukei people. Talanoa, when used effectively, can be an excellent pedagogical tool used in tertiary institutions (Halapua, 2002; Otunuku, 2011; Vaioleti, 2006). Through the creation of iTaukei courses and programs the CAS has earned a reputation and is a leader in indigenous studies honouring the indigenous worldviews.

\section{Promotion of Multi-cultural tolerance and Understanding}

Raising tolerance for people of different ethnic and racial groups is one of the goals of the CIS. Without tolerance, there can be a lot of tension or even conflict as a result of miscommunication in society. Literature on multiculturalism reverberates_that effective inter-cultural communication is critical to the establishment of favourable inter-group relations (Tien \& David, 2011). Subsequently, the CIS offers a number of cross cultural activities that involves iTaukei students as well as Fijian students. However, the CIS does not offer any conversational courses in Hindi language and this has been raised by majority of the students during the interviews. They believed that a basic communication course could be developed to synergize better tolerance and understanding amongst all the students from different cultural and ethnic backgrounds.

Tien and David (2011) further assert that communication is the heart of all human relationships and sincere intercultural communication, people regardless of group or cultural orientation, can work together to achieve great things. Effective communication can ultimately remove walls and barriers of misunderstanding that separate human beings. Activities like celebrating Diwali, which is an Indian festival of lights has helped in shaping the multicultural landscape in Fiji creating tolerance and better understanding amongst all people. The whole idea of intercultural communication is when one communicates with people from different cultures, one will learn about their values, history, habits and personality. Thus, through communication, one realizes that there is not only one way or one perspective of seeing things but there are many other ways too; for instance, from the different culture and religious perspectives. Through communication too, one will begin to understand the need to be tolerant towards differences and see then as strengths and appreciate them. This suggests a possible relationship between tolerance and inter-cultural communication, that can be furthered explored by expanded study and analysis by academics is recommended.

\section{Future Initiatives of CIS}

The rich cultural practices, knowledge systems and cultural expressions of the iTaukei people are a source of great strength, resilience and pride. Strong cultural identity is fundamental to Indigenous health and social and emotional wellbeing. Initiatives that strengthen Indigenous culture are therefore important to the CIS and as such, it also has a few future plans: 


\section{Special Building for CIS}

The CIS is currently based in a small room that houses two staff members. The CIS operates from this office while two other staff members are located in an adjacent office. Lectures and preparation of cultural items are held in normal lecture rooms. The CIS is looking for funds to establish a building of its own where it can fully offer all the courses and set it up depicting a truly iTaukei environment. One of the staff members claimed that: Having a special building with indigenous architectural design will look better and entice more students to enrol in our courses. It will be more spacious and we will be able to display our arts and crafts (L2, 2014).

While one of the students had the following to say:

As a student, I think there should be a building in shape of a bure where we can have all our classes. Also here we can be taught meke and weaving of mats. We also need a kitchen where we can learn how to prepare vakaloo (puddings). In doing so we can know what we learn in our iTaukei classes $(\mathrm{P} 18,2014)$.

Universities that offer indigenous studies globally have special centres well equipped with amenities required to host and deliver relevant programs (Bandias et al., 2014). For example, The University of New England has the Oorala Aboriginal Centre, which is a teaching, research and study support centre for internal and external Aboriginal and Torres Strait Islander students. They offer academic advice, tutorial assistance, have a computer room, a resource library, tutorial rooms and a student common room for relaxation and study. The CIS looks forward to having a similar centre where all the services can be located in one building. In doing so, CIS will value and respect the Indigenous knowledge systems as a vital part of the knowledge capital of Fiji.

\section{Dance and Cultural Group}

Apart from having a rich cultural background, the iTaukei are graceful dancers and performers. In essence, the CIS is determined to revive the ancient dance practices and cultural norms that are slowly diminishing in view of contemporary and western music. Their decision is based upon concerns with cultural conservation and development. According to the CIS staff members the revival of ancient dance practices meant trying to remember, record, relearn and perpetuate dances only seen during olden days. The CIS further intend to set up a unit or a dance group that would be well trained and they could perform at many of the tourist hotels and resorts in the western division. According to one of the lecturers (L3, 2014) "this could be an income generating exercise for the CIS at the same time they would market the CIS and the university".

Participation in artistic and cultural activities enables iTaukei to reinforce and preserve living culture, and maintain connection to family and traditional country which, in turn, develops identity, sense of place and self esteem in the building of strong cultural foundations. There is plethora of literature supporting the views that indigenous culture and tradition needs to be preserved and protected not only for the sake of identity but these attributes can contribute towards self employment and a decrease in abuse, neglect, and undue indulgence in criminal activities (Aseron et al., 2013; Bandias et al., 2014; Battiste \& Henderson, 2009; De France, 2013; Greenwood \& Leeuw, 2007; Maslen, 1999; Sillitoe, 1998; United Nations, 2008).

\section{Handicraft Centre}

The iTaukei people have a rich heritage in crafts and skill. The CIS believes that there are many wood carvers and mat weavers in nearby villagers who can be temporarily employed to teach these skills to our students. Students will be able to use these knowledge and skills in setting up their own workshops and create employment in villages and in rural settings. For there are many handicraft shops in urban centres and throughout the many hotels and resorts in Fiji that would be keen to buy the items produced. Similar to the Fijian context, subsequent literature purports that although Aboriginal community art centres are not conventional businesses they operate in communities where, enterprise and employment opportunities are extremely limited, and they fulfill important socio-cultural and training functions in addition to their commercial activities (Wright, 2000).

Subsequently, CIS intends to venture into commercial paintings, weaving and flower arrangements in an attempt to empower even village people with entrepreneurial skills. Options would be provided to students and prospective adults (schools leavers) so that they could work according to their knowledge and ability to learn appropriate skills. Through paintings the iTaukei people have preserved many of their traditional stories and legends. The cultural aspect of the paintings is paramount to them but they would enjoy the recognition and financial reward their work would bring. There is no denying the income from art is important to artists as they will be able to earn a better living through self employment. In one of the most dramatic examples of cultural empowerment in Fiji today, is that native peoples are establishing their own cultural committees, village archives, village handicraft centres and historic preservation programs (Ministry of iTaukei Affairs, 2011).

\section{Building capacity of indigenous staff}

The CIS staff members unanimously agreed that they all needed capacity strengthening in the areas of iTaukei studies. Capacity strengthening is based on a strengths-based perspective that all people have 
knowledge and skills and people can improve accordingly. Most of the staff at the CIS has Masters Degree but not in indigenous studies. They believe they all need professional development in specific areas of indigenous knowledge and culture. Strengthening Indigenous organizational capacity is a context-dependent process. It needs to be carried out within a developmental approach requiring collaboration, trust and long-term commitment. Findings fully support the argument by Maslen (1999) that well qualified indigenous staff will be able to better support the students and will no doubt enhance indigenous inspirations, cultural ceremonies and languages. Strengthening the capacity of the staff is beneficial in its own right. According to empirical data capacity building in indigenous people also improves the governance which, in a cyclical process of improvement, is the precursor to capacity strengthening for further sustainable development (Tsey, McCalman, Bainbridge, \& Brown, 2012). Providing staff with opportunities to improve and strengthen their abilities and knowledge will be an investment for the University at large.

\section{Reviewing of services and programs}

Most of the students ( 85 percent) were happy with the programs offered by the CIS while a few suggested that conversational Hindi should also be offered. While there is a generic course HIC111 spoken Hindi for beginners, students believed it should be more contextual and this should be included in all the programs. Majority of the students agreed that CIS needed to play a more helpful role in regards to student support services such as mentoring and coaching in assignment write ups. Some of the students raised concern in regards to the lack of cross-cultural activities organised by the CIS. One of the students (P6, 2014) stated that "we only have cross cultural activities when we have some functions, like the creative circle at the University but we need to have more." Creative Circle is one such event that allows students to celebrate the richness in diversity through a variety of cross cultural activities. It provides opportunities for students to display their talents and take part in cross cultural activities such as art \& craft, dance and music.

The single greatest remedy to the issues discussed so far involves unbiased recognition of the CIS as the premier centre for not only preserving and promoting iTaukei culture and traditions but also for encouraging excellence in education by stakeholders, Ministry of iTaukei Affairs, Ministry of Education Culture and Heritage and other social service organizations in Fiji and abroad. In a subtle way the CIS has contributed a lot towards developing an inclusive and united Fiji but has the scope to offer a lot more. It requires a productive learning environment for its students and adequate resources to fully showcase its capabilities and products. It is high time the true value of CIS is recognized and assisted so that it becomes a fully fledged centre with well equipped facilities to fully deliver the initiatives as discussed earlier.

\section{Conclusion}

Due to the relatively small nature of the CIS and with a manageable research sample, one should proceed with caution when seeking to extrapolate findings from this research across other such institutions. The degree of fit between a sample and the target population about which generalizations can be made is a common challenge in many studies (Minichiello et al., 2008; Rhodes, Bowie, \& Hergenrather, 2003). However, this research provides a strong foundation for further research and could extend the scope of investigation in the domain of indigenous education and research incorporating indigenous knowledge and approaches in Fiji and abroad.

This paper attempts to offer an overview of the courses and programs regarding iTaukei language and culture offered by the CIS. While the paper is more informative in nature about indigenous pedagogies and practices, it has revealed a holistic interpretation of the various courses, programs and activities offered by an indigenous learning centre. It seems, then, that despite being small in nature the CIS has made its impact not only on the lives of the iTaukei students but the community at large at the University. With the many initiatives in the pipeline and with support from the university, well wishers and external funders, I am confident that the CIS will become a centre of attraction and excel in years to come.

\section{Reference}

[1]. Ali, W. (2004). Challenges in Multi-class Teaching: Case study in a Fiji school. Unpublished Master's thesis. University of the South Pacific.

[2]. Aseron, J., Wilde, S., Miller, A., \& Kelly, S. (2013). Indigenous Student Participation In Higher Education: Emergent Themes And Linkages. Contemporary Issues in Education Research (Online), 6(4), 417.

[3]. Bandias, S., Fuller, D., \& Larkin, S. (2014). Indigenous Students In The Tertiary Education Sector. Journal of International Education Research, 10(3), 179-n/a.

[4]. Battiste, M., \& Henderson, J. Y. (2009). Naturalizing Indigenous Knowledge in Eurocentric Education. Canadian Journal of Native Education, 32(1), 5-18,129-130.

[5]. Creswell, J. W., \& Clark, V. L. P. (2007). Designing and Conducting Mixed methods Research. London: Sage Publications.

[6]. De France, M. d. C. R. (2013). Indigenous/Aboriginal Pedagogies Restored: Courses And Programs In The Faculty Of Education At The University Of Victoria. International Education, 43(1), 85-100.

[7]. DeFrance, M. d. C. R. (2013). Indigenous/Aboriginal Pedagogies Restored: Courses And Programs In The Faculty Of Education At The University Of Victoria. International Education, 43(1), 85-100. 
[8]. Doxtater, M. G. (2004). Indigenous Knowledge in the Decolonial Era. American Indian Quarterly, $28(3 / 4), 618-633$.

[9]. Farrelly, T., \& Nabobo-Baba, U. (2014). Talanoa as empathic apprenticeship. Asia Pacific Viewpoint, 55(3), 319-330

[10]. Gamage, S. (2001). Indigenous People's and Protected Areas in South and Southeast Asia: From Principles to Practice. Journal of Contemporary Asia, 31(4), 562-565.

[11]. Gravelle, K. (2000). Fiji's Heritage: A History of Fiji. Nadi: Tiara Enterprises.

[12]. Greenwood, M., \& Leeuw, S. d. (2007). Teachings From the Land: Indigenous People, Our Health, Our Land, and Our Children. Canadian Journal of Native Education, 30(1), 48-53,189.

[13]. Halapua, S. (2002). Tanoa Process: The Case of Fiji. from http://unpan1. un.org/intradoc/ groups/public/ documents/ un/unpan022610.pdf

[14]. Hill, J. C., \& Arlene Holland, S. (2002). Editorial: Indigenous education: Ways of knowing, thinking, and doing. McGill Journal of Education, 37(3), 281.

[15]. Liamputtong, P., \& Ezzy, D. (2008). Qualitative Research Methods (2nd ed.). Melbourne: Oxford University Press.

[16]. Lichtman, M. (2006). Qualitative Research in Education: A Users Guide. United States of America: SAGE Publications.

[17]. Lincoln, Y. S., \& Guba, E. G. (1985). Naturalistic Inquiry. Newbury Park, CA: Sage Publications.

[18]. Maslen, G. (1999). Australia inaugurates its first university for Indigenous people. The Chronicle of Higher Education, 45(47), 1.

[19]. McGregor, L. (2003). Analysis: A long way from home: Indigenous people the world over were evicted from their land in the name of tourism and conservation. The battle for restitution goes on. The Guardian, pp. 27-21.27, from http://ezproxy.unifiji.ac.fj:2072/docview/246041967?accountid=17235

[20]. Mehta, K., Alter, T. R., Semali, L. M., \& Maretzki, A. (2013). AcademIK Connections: Bringing Indigenous Knowledge and Perspectives into the Classroom. Journal of Community Engagement and Scholarship, 6(2), 83-91.

[21]. Merriam, S. B. (1998). Qualitative Research and Case Study Applications in Education. San Francisco: Jossey-Bass Publishers.

[22]. Miles, M. B., \& Huberman, M. A. (1994). An Expanded Source Book, Qualitative Data Analysis. London: Sage Publications.

[23]. Minichiello, V., Aroni, R., \& Hays, T. (2008). In-Depth Interviewing (3rd ed.). Sydney: Pearson Education Australia.

[24]. Ministry of Information. (2006/7). Fiji Today. Suva: Government Printery.

[25]. Ministry of iTaukei Affairs. (2011). Annual Corporate Plan. Suva.

[26]. Otunuku, M. a. (2011). Talanoa: How can it be used effectively as an indigenous research methodology with Tongan people? Pacific-Asian Education: The Journal of the Pacific Circle Consortium for Education, 23(2), 43-52.

[27]. Rasmus, S. M. (2002). Repatriating Words: Local Knowledge in a Global Context. American Indian Quarterly, 26(2), 286-307.

[28]. Rhodes, S. D., Bowie, D. A., \& Hergenrather, K. C. (2003). Collecting behavioural data using the world wide web: Considerations for researchers. Journal of Epidemiology and Community Health, 57(1), 68-73.

[29]. Rose, K., \& Webb, C. (1998). Analyzing Data: Maintaining Rigor in a Qualitative Study. Qualitative Health Research, 8(4), 556 562

[30]. Sayed-Khaiyum, A. (2014). FijiFirst Our Manifesto. Suva: Quality Print Limited.

[31]. Sharma, A. N. (2000). Vocational Educational and Training in Fiji. New Delhi: Anamika Publications.

[32]. Sillitoe, P. (1998). The Development of Indigenous knowledge: A New Applied Anthropology Current Anthropology, 39(2), 223252 .

[33]. Sockbeson, R. C. (2009). Waponahki Intellectual Tradition of Weaving Educational Policy. Alberta Journal of Educational Research, 55(3), 351-364.

[34]. Stake, R. E. (1995). The Art of Case Study Research. Thousand Oaks: Sage Publications.

[35]. Stake, R. E. (2000). Case Studies. In N. K. Denzin \& Y. S. Lincoln (Eds.), Handbook of Qualitative Research. London: Sage Publications

[36]. Teddlie, C., \& Tashakkori, A. (2009). Foundations of Mixed methods Research: Integrating Quantitative and Qualitative Approaches in the Social and Behavioral Sciences. Thousand Oaks: SAGE Publications Inc.

[37]. The Government Of The Republic OF Fiji. (2013). Constitution Of The Republic OF Fiji. Suva: Government Printery.

[38]. Tien, W. Y. M., \& David, M. K. (2011). Inter-Ethnic Tolerance and Cross-Cultural Communication: Its Relationship and Importance in a Multicultural Society. International Journal of Arts \& Sciences, 4(17), 345-357.

[39]. Tsey, K., McCalman, J., Bainbridge, R., \& Brown, C. ( 2012). Improving Indigenous community governance through strengthening Indigenous and government organisational capacity. Retrieved Resource sheet no. 10 produced for the Closing the Gap Clearinghouse, from http://www.aihw.gov.au/uploadedFiles/ClosingTheGap/Content/Publications/2012/ctgc-rs10.pdf

[40]. United Nations. (2008). United Nations Declaration on Rights of Indigenous People. New York: United Nations.

[41]. Vaioleti, T. M. (2006). Talanoa Research Methodology: A developing Position on Pacific Research. Waikato Journal of Education, 12 .

[42]. Ward, M. K. (2011). Teaching Indigenous American Culture and History: Perpetuating Knowledge or Furthering Intellectual Colonization? Journal of Social Sciences, 7(2), 104-112.

[43]. Williamson, J., \& Dalal, P. (2007). Indigenising the Curriculum or Negotiating the Tensions at the Cultural Interface? Embedding Indigenous Perspectives and Pedagogies in a University Curriculum. The AustralianJournal of Indigenous Education, $36,51-58$.

[44]. Wilson, S. (2008). Research is Ceremony: Indigenous Research Methods. Canada: Halifax.

[45]. Wright, F. (2000). The Art and Craft Story: The Survey of 39 Aboriginal Community Art Centres in Remote Australia, Summary and Recommendations (Vol. 2). Canberra: ATSIC.

[46]. Yin, R. K. (2003). Case Study Research: Designs and Methods (3rd ed.). New Delhi: SAGE Publications Inc. 